\title{
VESTÍGIOS, RUÍNAS E OS SENTINELAS DA MEMÓRIA FERROVIÁRIA DO RIO GRANDE DO SUL: ENSAIO ETNOFOTOGRÁFICO NAS CIDADES DE PELOTAS E PORTO
} ALEGRE

\author{
Yuri Schönardie Rapkiewicz ${ }^{1}$ \\ Guillermo Stefano Rosa Gómez ${ }^{2}$
}

Este ensaio envolve um mergulho nas camadas do tempo, vivenciadas e transmitidas por sujeitos que narram uma cultura operária, dos múltiplos ofícios que integram e integraram o sistema ferroviário brasileiro. Através de um processo de escuta atenta (CARDOSO DE OLIVEIRA, 2006) e de uma negociação subjetiva, nos vinculamos, em um contexto antropológico e etnográfico, a trabalhadores ferroviários aposentados. Estas fotografias dialogam com nossos contextos de pesquisa, nas cidades de Pelotas e Porto Alegre, ambas no Rio Grande do Sul (RS). Nomeamos esses personagens de sentinelas, primeiro fazendo referência à Jacques Le Goff (1990) que enfatiza o papel de determinadas figuras para a manutenção da memória de um grupo, o que conceitua como "homens-memória" (idem, p. 370). A característica enfatizada, presente no termo sentinela, é a de vigília e de guarda constante. São as ações, as narrativas e as imagens desses personagens que se inserem em um projeto de memória coletiva das sociedades urbanas (ECKERT \& ROCHA, 2013) e inscrevem-se como um esforço de duração (BACHELARD, 1998).

Yuri Schönardie Rapkiewicz iniciou sua pesquisa entre os ferroviários em 2010, mesmo ano em que ingressou como bolsista de I.C. no Núcleo de Antropologia Visual (NAVISUAL/PPGAS/UFRGS). A investigação foi gestada no interior de um projeto maior (inserido no núcleo supracitado) intitulado "Trabalho e Cidade: Antropologia da Memória do Trabalho na Cidade Moderno-Contemporânea" (CAPES/PNPD), que seguia a tradição dos estudos etnográficos com imagens, enfocando a memória do trabalho, de diferentes profissões, na cidade de Porto Alegre. O projeto culminou em variadas publicações, entre as quais um volume em que o relato do processo etnográfico entre os ferroviários foi publicado como capítulo de livro, organizado por Ana Luiza Carvalho da Rocha e Cornelia Eckert. (RAPKIEWICZ \& ECKERT, 2015)

Seu Trabalho de Conclusão de Curso em Ciências Sociais (UFRGS) (RAPKIEWICZ, 2014), foi orientado pela professora Cornelia Eckert, e dialogando com a Antropologia Visual e Urbana,

\footnotetext{
${ }^{1}$ Mestrando em Antropologia Social Universidade Federal do Rio Grande do Sul (PPGAS /UFRGS). yrapkiewicz@gmail.com.

${ }^{2}$ Mestrando em Antropologia Social, Universidade Federal do Rio Grande do Sul (PPGAS /UFRGS). guillermorosagomez@gmail.com
} 
analisou as imagens e os espaços da ferrovia em Porto Alegre, bem como os itinerários e redes de sociabilidade, nos quais estavam inseridos os ferroviários aposentados. Privilegiou as reuniões sindicais e o processo de regularização fundiária da vila ferroviária, local de habitação onde persistem muitos dos aposentados e suas famílias. Nesse contexto, ainda, organizou uma exposição fotográfica como forma de restituição e circulação dos dados reunidos no período de pesquisa.

Para o presente ensaio, o pesquisador valoriza a figura de Hélio Bueno da Silveira. Este ferroviário aposentado trabalhou na Via Permanente (reparação e manutenção das linhas) e no setor de comunicação social da Rede Ferroviária Federal (RFFSA). No alto dos seus 74 anos, é um importante articulador da memória desta categoria. Gestor do Grêmio Esportivo Ferrinho (agremiação localizada ao lado da vila ferroviária e aos fundos da área operacional da ferrovia) este senhor mantém uma incrível coleção de objetos, papéis e fotografias sobre o universo ferroviário. Atualmente se esforça para que o prédio seja reconhecido pelo poder público como um centro cultural ativo, aberto a comunidade local.

Guillermo Gómez começa a pesquisar o universo ferroviário em seu Trabalho de Conclusão de Curso em Ciências Sociais (GÓMEZ, 2015) pela Universidade Federal de Pelotas (UFPel), orientado por Claudia Turra Magni e inserido no Laboratório de Ensino, Pesquisa e Produção em Antropologia da Imagem e do Som (LEPPAIS/UFPel). Dedicou-se a compreender, por meio das narrativas de aposentados, a estrutura, os processos de trabalho, a divisão hierárquica e suas ressonâncias nos apelidos, nos causos e nas piadas, narrativas características do ethos deste grupo profissional. A pesquisa de campo valeu-se da observação flutuante (PÉTONNET, 2008) pelos espaços da antiga vila operária de Pelotas, assim como a observação participante nas casas dos moradores e na delegacia do sindicato ferroviário. A investigação também inseriu-se em um projeto de extensão, coordenado pela professora Claudia Turra Magni, intitulado Vida nos Trilhos: Memorial da Estação Férrea, que envolveu uma equipe interdisciplinar e produziu uma exposição itinerante composta por doze banners e um vídeo documentário.

Nesta narrativa visual, prioriza dois interlocutores: Orlando Chagas, de 58 anos, é delegado sindical de Pelotas e maquinista aposentado, envolveu-se como curador da exposição itinerante, negociando sua ida a Porto Alegre ${ }^{3}$. O sindicato constitui um importante espaço de sociabilidade para os aposentados, que reúnem-se ocasionalmente para discutir política, processos salariais que estão tramitando na justiça, causos e memórias da profissão.

${ }^{3}$ Este processo de uma Antropologia Compartilhada, juntamente com a divulgação da exposição foi noticiado pela página da Universidade Federal de Pelotas e pelo Diário da Manhã, disponível online:http://diariodamanhapelotas.com.br/site/projeto-resgata-historia-da-estacao-ferrea 
Rubem Medeiros, 80 anos, ingressou no trabalho ferroviário em uma empresa ainda pertencente ao Estado (Viação Férrea do Rio Grande do Sul/VFRGS), na qual desempenhava um trabalho braçal, na Via Permanente. Também trabalhou como Agente da Estação de Pelotas, nos armazéns de carga e no licenciamento de trens. Se aposentou em 1988, quando foi homenageado pela direção da empresa em razão dos cem anos da Abolição da Escravatura, recebendo uma placa de ouro com os dizeres: "A você que na sua pessoa representa a coragem e a luta do povo negro junto à história da Rede Ferroviária do Rio Grande do Sul, nossa homenagem e gratidão". Sua postura de "homem-memória" (LE-GOFF, 1990), evidencia-se, também, na preservação dos documentos: guarda com ele os envelopes em que recebia seu salário - que inicialmente vinham no trem pagador - que datam desde seu primeiro ano de trabalho, 1957, até sua aposentadoria.

No momento presente, estamos inseridos no Programa de Pós-Graduação em Antropologia Social da Universidade Federal do Rio Grande do Sul (PPGAS/UFRGS), cursando o mestrado. No âmbito do Núcleo de Antropologia Visual (NAVISUAL) compartilhamos a orientação da professora Cornelia Eckert. Nossos interesses de pesquisa convergiram na possibilidade de elaborarmos um ensaio etnofotográfico sobre a ferrovia, suas ruínas e seus narradores. Partindo da filiação comum à Etnografia da Duração (ECKERT \& ROCHA, 2013), investigamos o passar do tempo, no envelhecimento dos corpos e das ferrovias e, ao mesmo tempo, a "insubordinação" destes sujeitos à "ação corrosiva do tempo" (idem, p.32). Cientes desta transformação do universo de trabalho e da matriz ferroviária de transportes, os sentinelas permanecem em vigília. Suas memórias vibram "em uníssono" com sua comunidade afetiva e de trabalho (HALBWACHS, 2006, p.47). Tecem suas narrativas, que, sobrepondo as camadas do tempo, entre discursos e práticas cotidianas, configuram a duração de um singular modo de vida.

\section{REFERÊNCIAS}

BACHELARD, Gaston. A dialética da duração. São Paulo, Editora Ática, 1988

CARDOSO DE OLIVEIRA, Roberto. O trabalho do antropólogo. São Paulo: Editora Unesp, 2006

GÓMEZ, Guillermo S.R. Cidade, Trabalho e Narrativa: Etnografia Urbana com Ferroviários Aposentados em Pelotas. Trabalho de Conclusão de Curso de Graduação em Ciências Sociais sob Orientação da Drª . Claudia Turra Magni. Pelotas/UFPel: IFISP, 2015.

HALBWACHS, M. A Memória Coletiva. São Paulo, Vértice, 1990. 
LE GOFF, Jacques. Memória. In História e memória. Campinas, SP Editora da UNICAMP, 1990. PETONNET, Colette. A observação flutuante: o exemplo de um cemitério parisiense. Antropolítica, no . 25, p.99-111. Niterói, 2008.

RAPKIEWICZ, Yuri Schönardie. Trilhar e continuar: estudo etnofotografico dos ferroviários de Porto Alegre e algumas reflexões antropológicas sobre a cidade, o trabalho e a memória. Trabalho de Conclusão de Curso de Graduação em Ciências Sociais sob Orientação da Dra $^{\mathrm{a}}$. Cornelia Eckert. Porto Alegre/UFRGS: IFCH, 2014.

RAPKIEWICZ, Yuri Schönardie; ECKERT, Cornelia. Entre trilhos e temporalidades: o tempo do trabalho nas memórias dos ferroviários aposentados de Porto Alegre. In: ECKERT, Cornelia; ROCHA, Ana Luiza Carvalho da (Org.). Etnografias do Trabalho, Narrativas do Tempo. Porto Alegre: Marcavisual, 2015. p. $276-303$

RICOEUR, Paul. O si e a identidade narrativa. O si-mesmo como um outro. Campinas, Papirus, 1991. p 28 a 38 e p 167 a 198.

ROCHA, Ana Luiza e ECKERT, Cornelia. O antropólogo na figura do narrador. In: O tempo e a cidade. Porto Alegre, UFRGS, 2005

ROCHA, Ana Luiza Carvalho e ECKERT, Cornelia. Etnografia da duração. Porto Alegre: Marcavisual,2013 

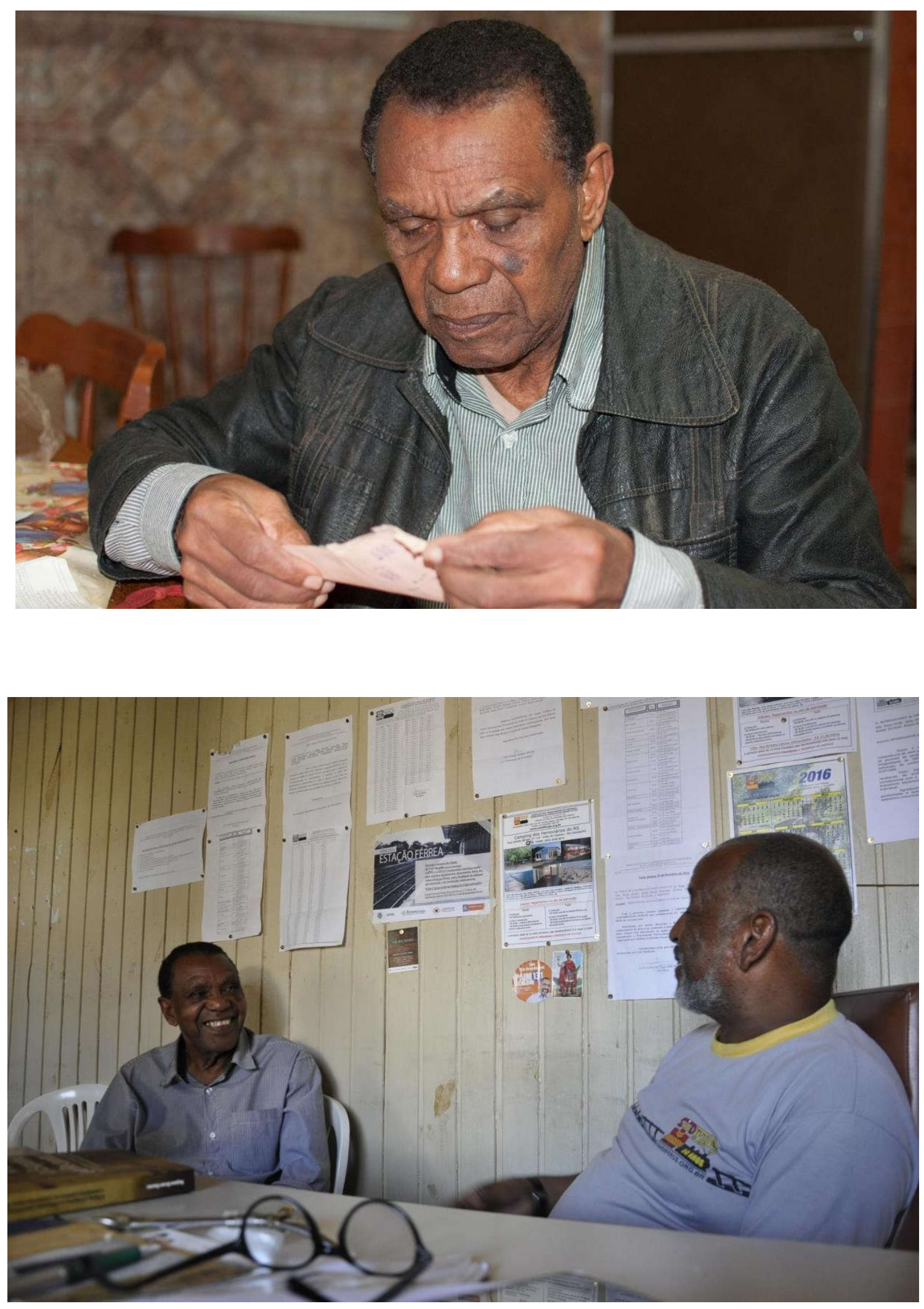

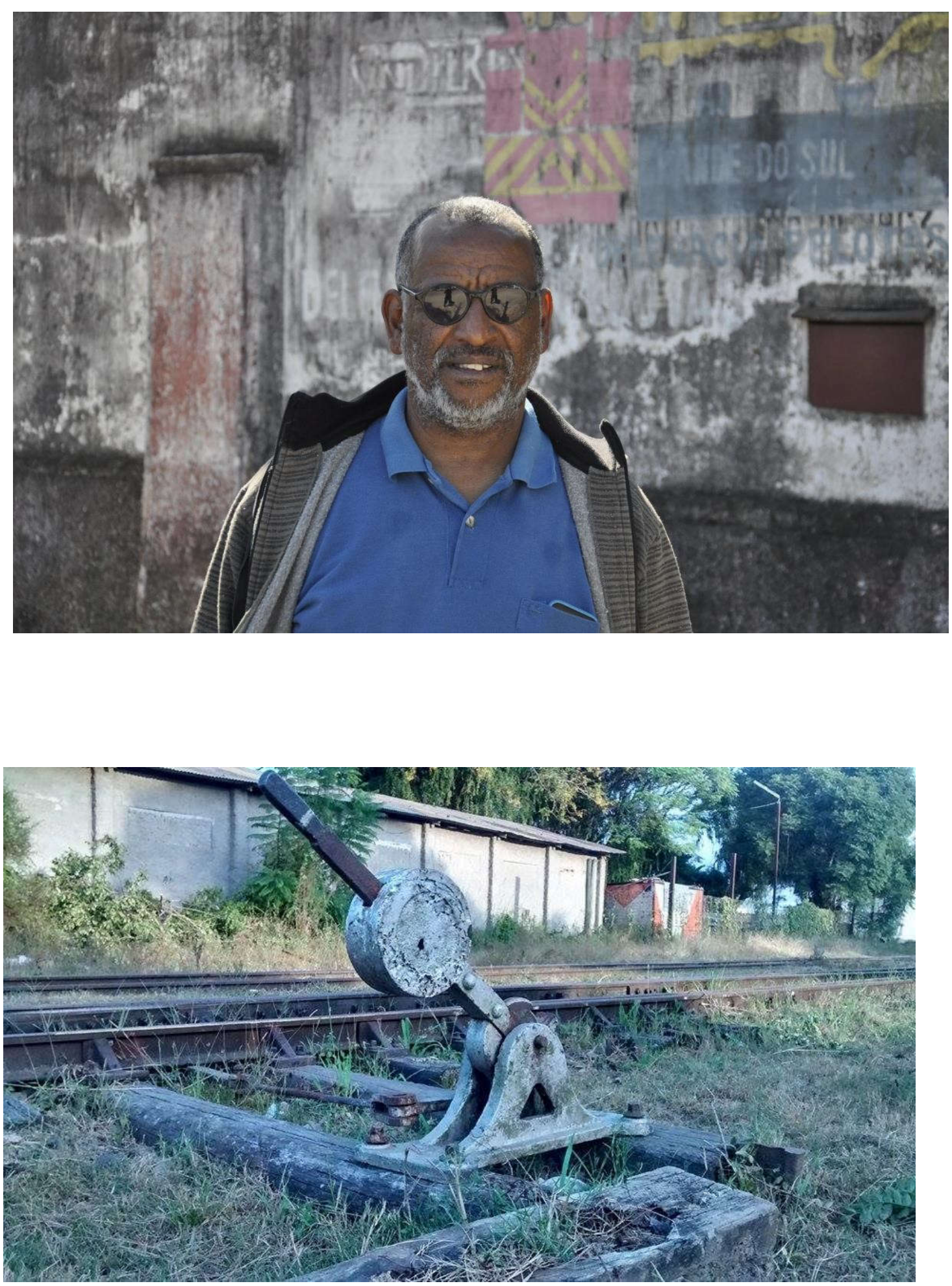

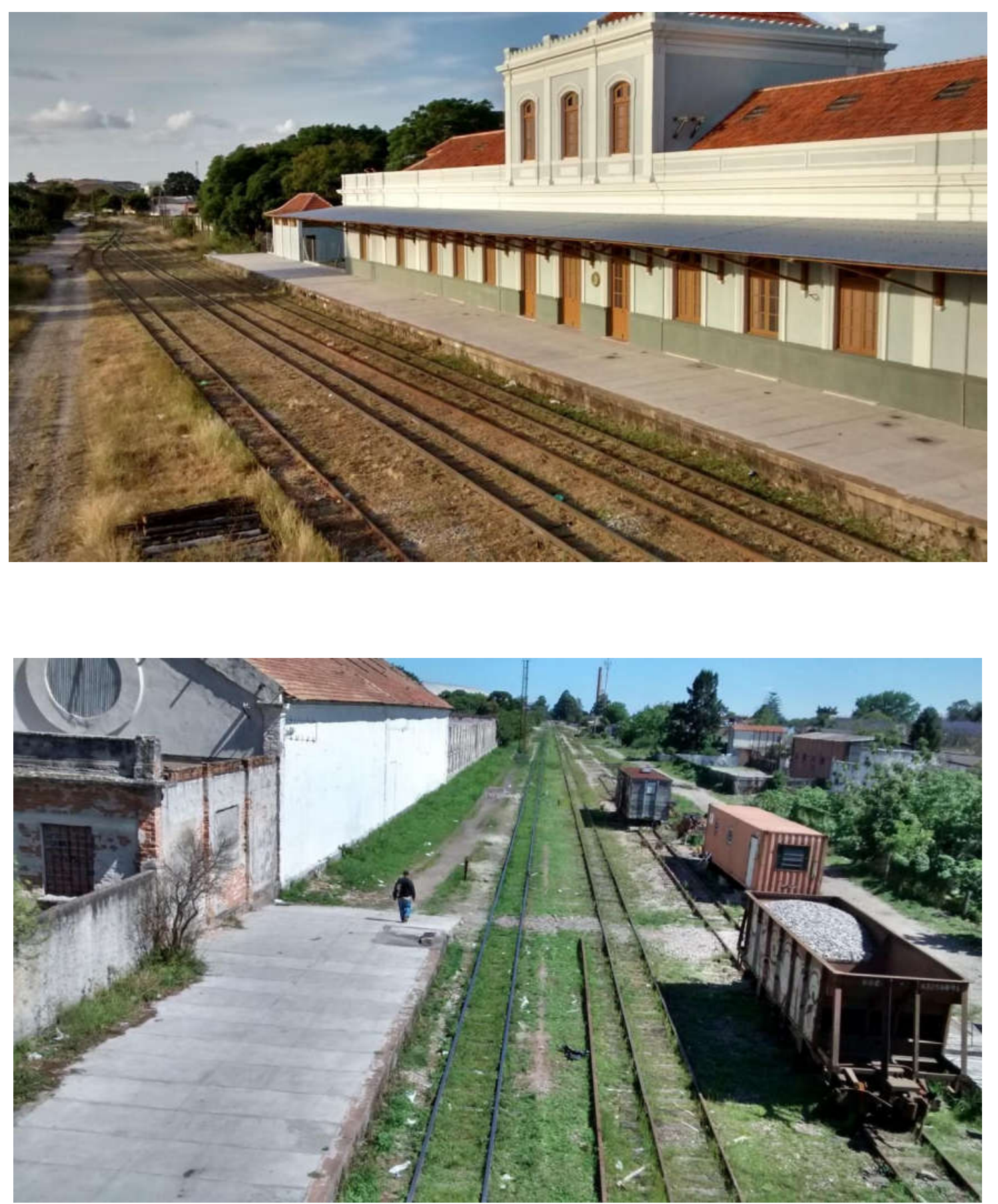


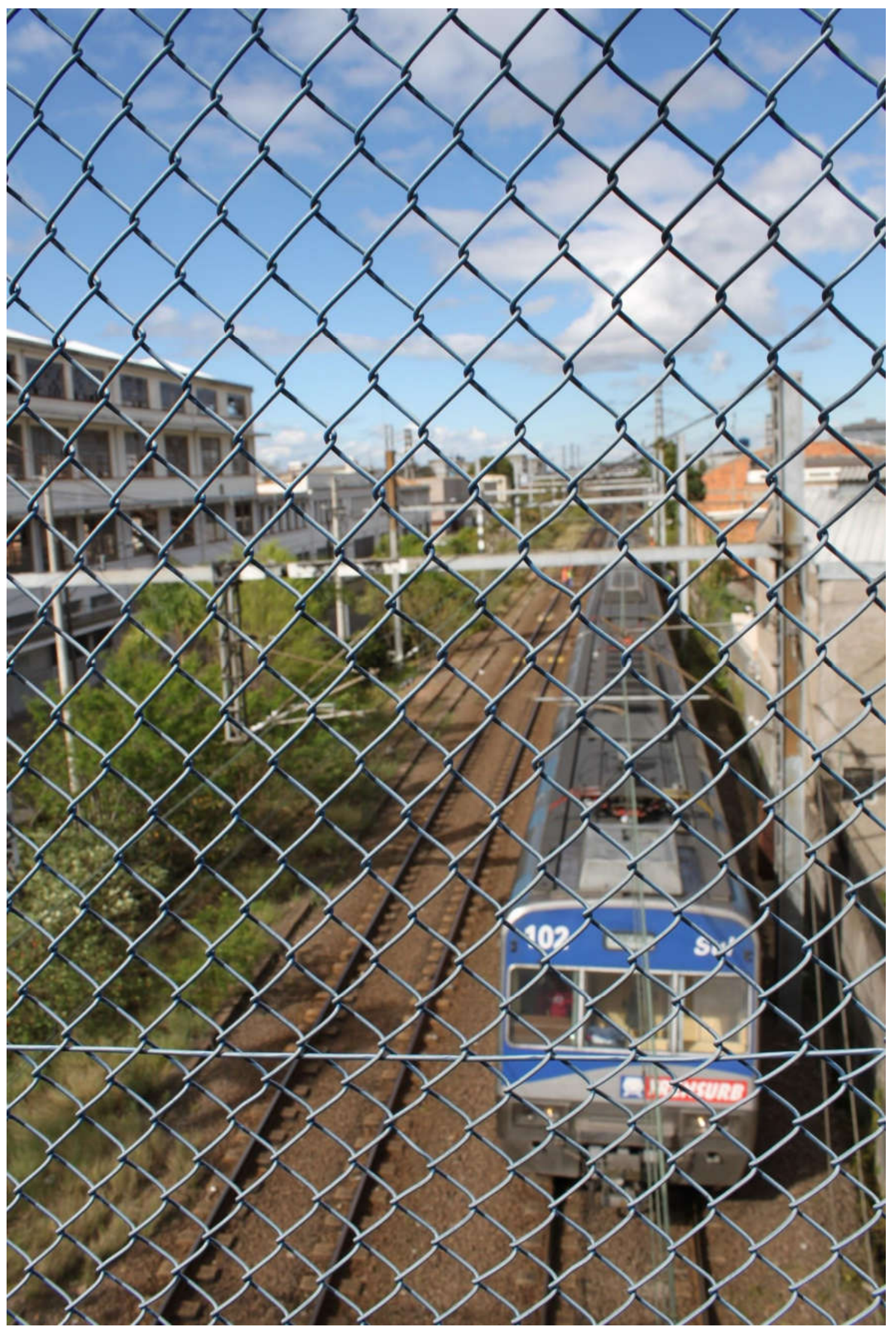



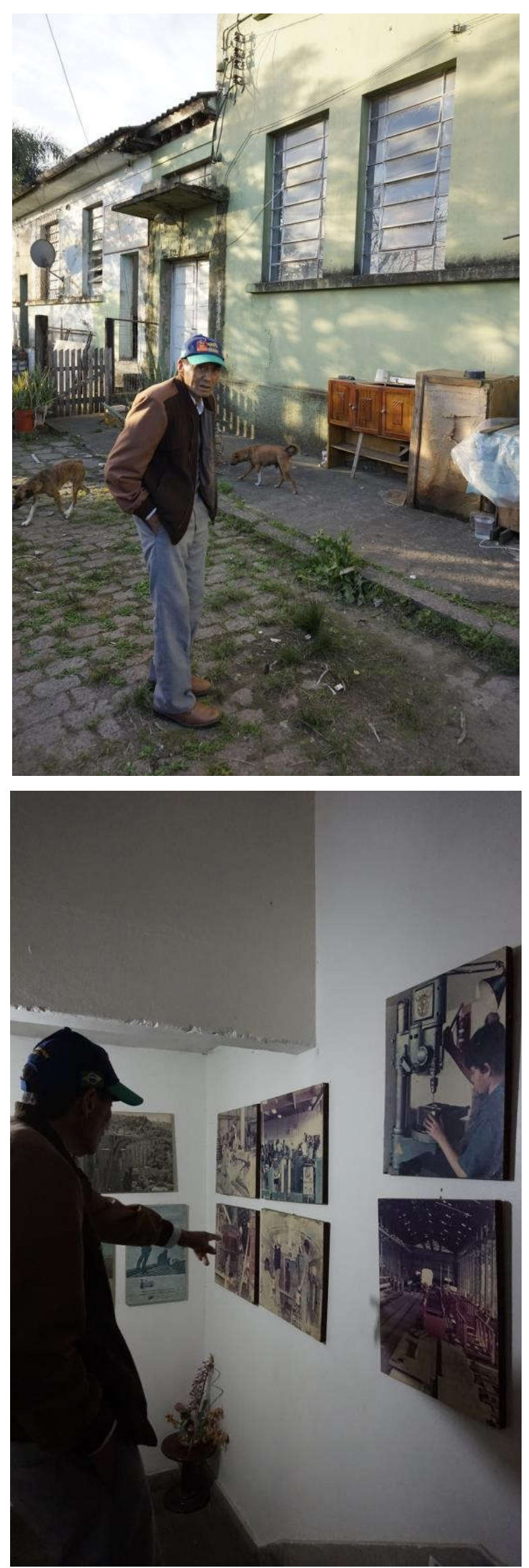

Nova Revista Amazônica - ANO IV - Volume 3 - DEZEMBRO 2016 - ISSN: 2318-1346 

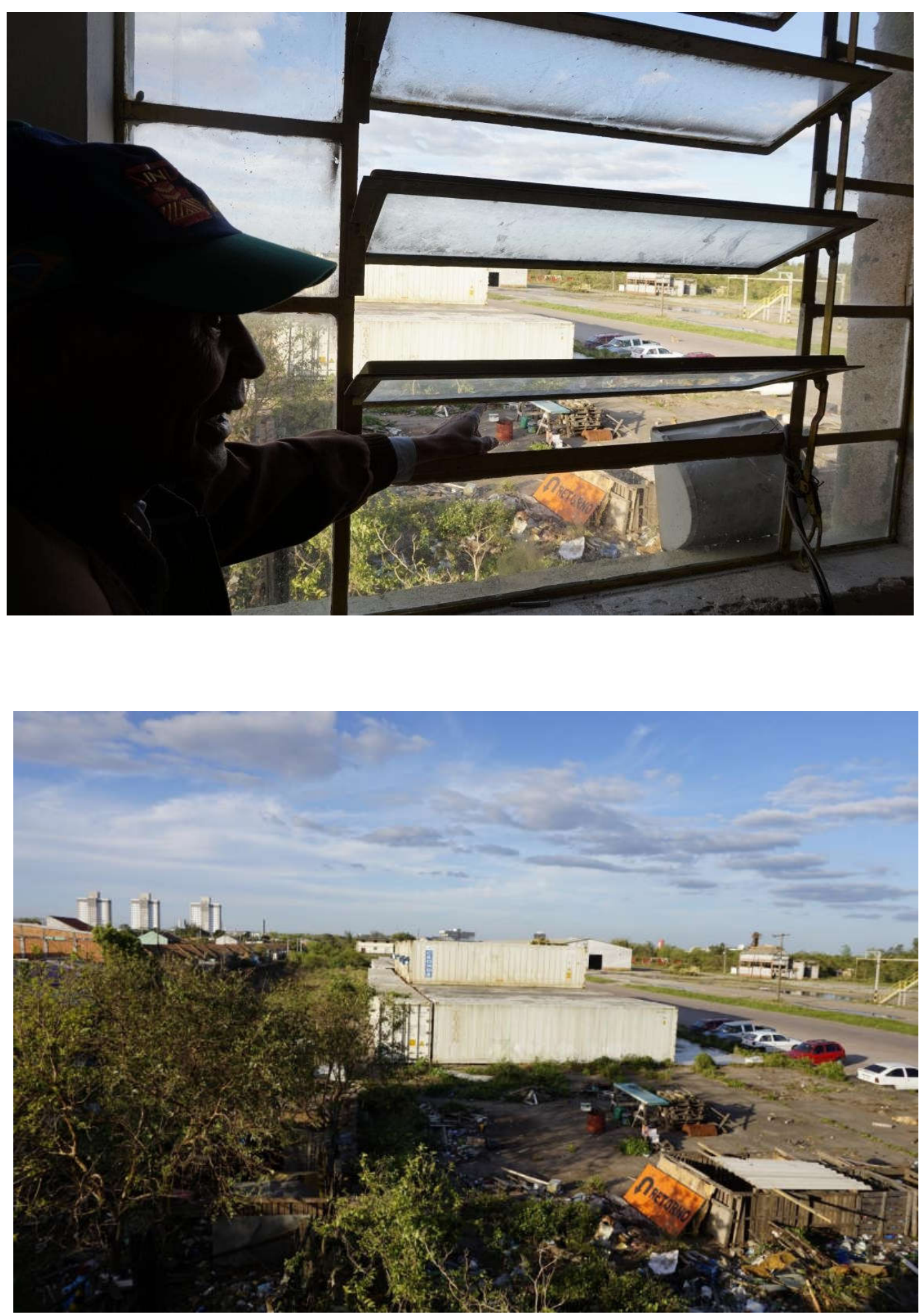


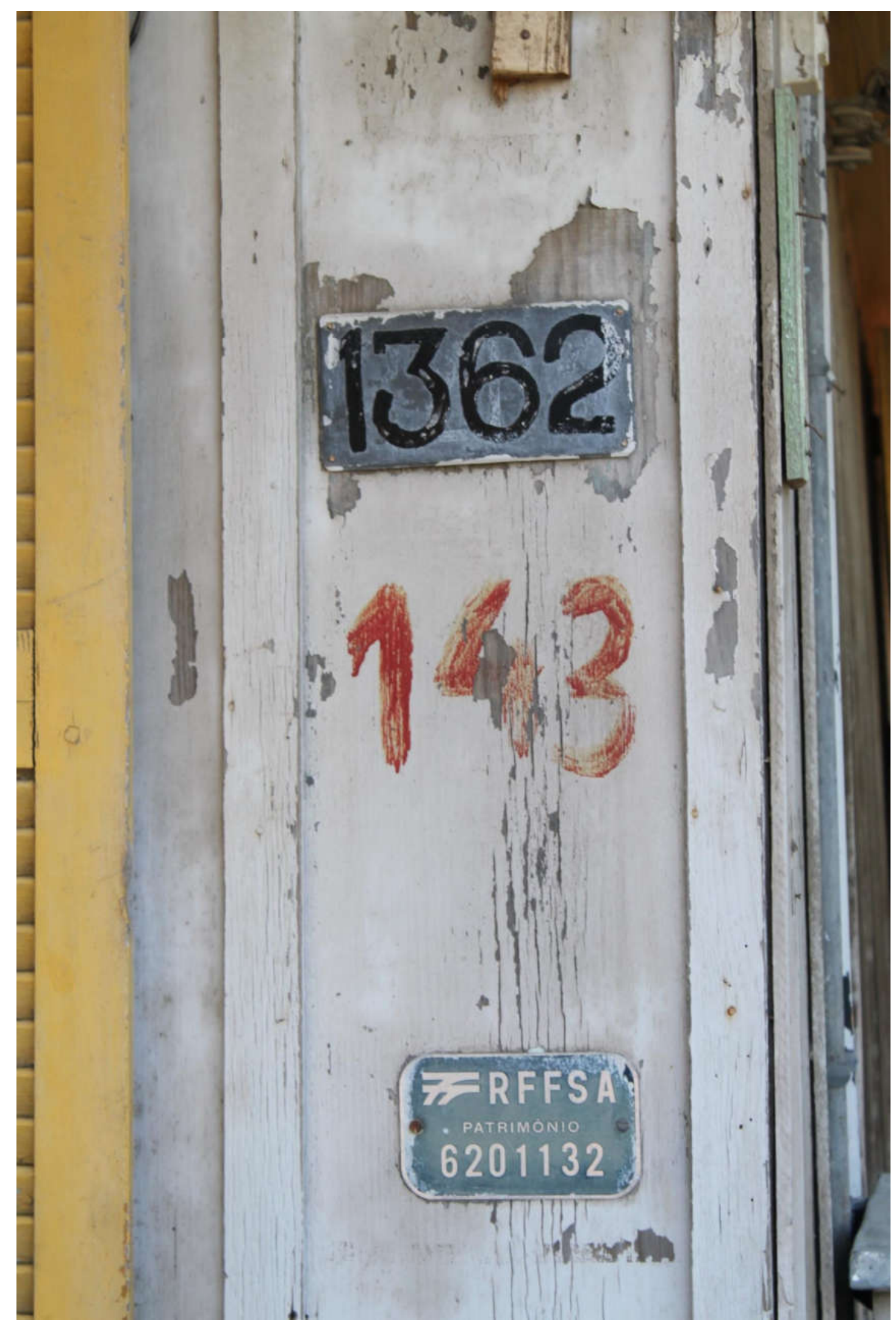



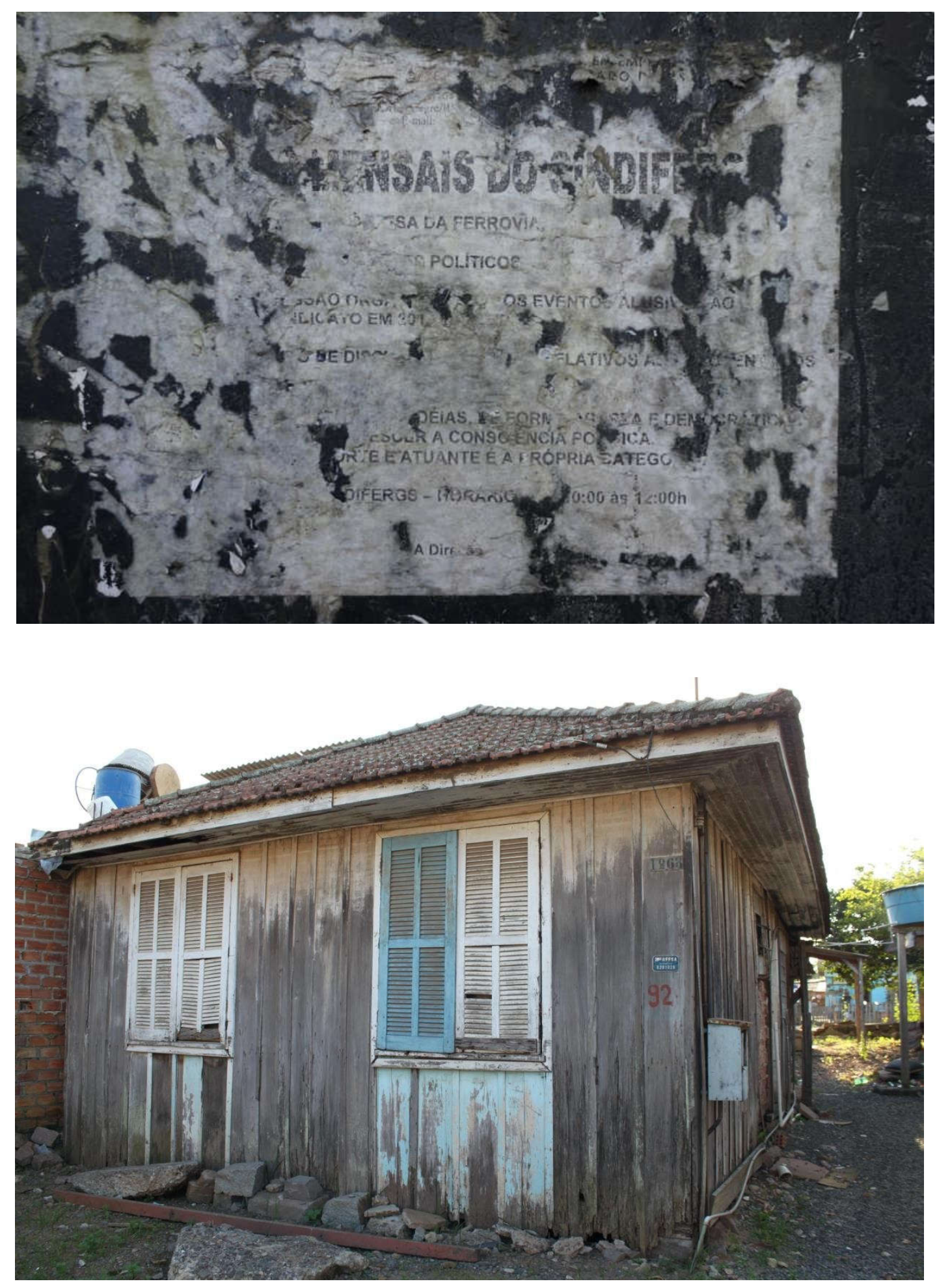


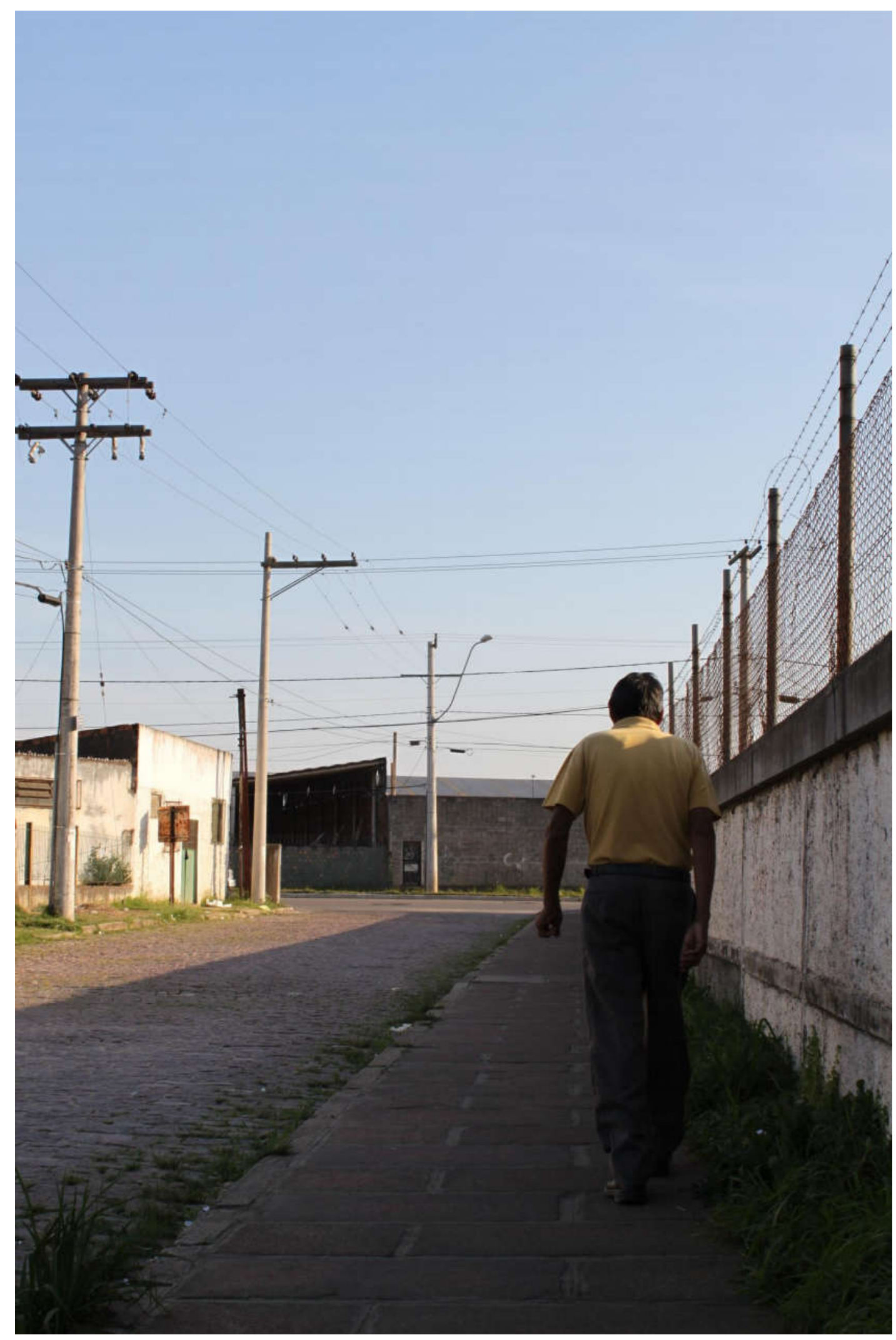

Nova Revista Amazônica - ANO IV - Volume 3 - DEZEMBRO 2016 - ISSN: 2318-1346 